University of Wollongong

Research Online

Australian Institute for Innovative Materials -

Papers

Australian Institute for Innovative Materials

$1-1-2013$

CO2 capture and gas separation on boron carbon nanotubes

Qiao Sun

University Of Queensland

Meng Wang

China University of Petroleum

Zhen Li

University of Wollongong, zhenl@uow.edu.au

Yingying $\mathrm{Ma}$

Chengdu University of Technology, China

Aijun Du

University Of Queensland

Follow this and additional works at: https://ro.uow.edu.au/aiimpapers

Part of the Engineering Commons, and the Physical Sciences and Mathematics Commons

Research Online is the open access institutional repository for the University of Wollongong. For further information contact the UOW Library: research-pubs@uow.edu.au 


\title{
CO2 capture and gas separation on boron carbon nanotubes
}

\begin{abstract}
Concern about the increasing atmospheric $\mathrm{CO} 2$ concentration and its impact on the environment has led to increasing attention directed toward finding advanced materials and technologies suited for efficient CO2 capture, storage and purification of clean-burning natural gas. In this letter, we have performed comprehensive theoretical investigation of $\mathrm{CO} 2, \mathrm{~N} 2, \mathrm{CH} 4$ and $\mathrm{H} 2$ adsorption on B2CNTs. Our study shows that $\mathrm{CO} 2$ molecules can form strong interactions with B2CNTs with different charge states. However, N2, $\mathrm{CH} 4$ and $\mathrm{H} 2$ can only form very weak interactions with $\mathrm{B} 2 \mathrm{CNTs}$. Therefore, the study demonstrates B2CNTs could sever as promising materials for CO2 capture and gas separation. 2013 Elsevier B.V. All rights reserved.
\end{abstract}

\section{Keywords}

carbon, capture, gas, nanotubes, separation, co2, boron

Disciplines

Engineering | Physical Sciences and Mathematics

\section{Publication Details}

Sun, Q., Wang, M., Li, Z., Ma, Y. \& Du, A. (2013). CO2 capture and gas separation on boron carbon nanotubes. Chemical Physics Letters, 575 (June), 59-66. 


\title{
$\mathrm{CO}_{2}$ Capture and Gas Separation on Boron Carbon Nanotubes
}

\author{
Qiao Sun ${ }^{1, *}$, Meng Wang ${ }^{2}$, Zhen $\mathrm{Li}^{3,{ }^{*}}$ Yingying $\mathrm{Ma}^{4}$ and Aijun $\mathrm{Du}^{5 *}$ \\ ${ }^{1}$ Centre for Computational Molecular Science, Australian Institute for Bioengineering \\ and Nanotechnology, The University of Queensland, Qld 4072, Brisbane, Australia. \\ ${ }^{2}$ Center for Bioengineering and Biotechnology, China University of Petroleum (East \\ China), Qingdao 266555, China. \\ ${ }^{3}$ Institute of Superconducting \& Electronic Materials, The University of Wollongong, \\ NSW 2500, Australia. \\ ${ }^{4}$ College of Materials and Chemistry \& Chemical Engineering, Chengdu University of \\ Technology, Chengdu 610059, China \\ ${ }^{5}$ School of Chemistry, Physics and Mechanical Engineering, Queensland University of \\ Technology, Brisbane, QLD 4001, Australia
}

Corresponding author: Qiao Sun, Zhen Li and Aijun Du

Email:_ q.sun@uq.edu.au; zhenl@uow.edu.au; aijun.du@qut.edu.au 


\begin{abstract}
Concern about the increasing atmospheric $\mathrm{CO}_{2}$ concentration and its impact on the environment has led to increasing attention directed toward finding advanced materials and technologies suited for efficient $\mathrm{CO}_{2}$ capture, storage and purification of cleanburning natural gas. In this study, we have performed comprehensive theoretical investigation of $\mathrm{CO}_{2}, \mathrm{~N}_{2}, \mathrm{CH}_{4}$ and $\mathrm{H}_{2}$ adsorption on $\mathrm{B}_{2} \mathrm{CNT}$ s. Our study shows that $\mathrm{CO}_{2}$ molecules can form strong interactions with $\mathrm{B}_{2} \mathrm{CNTs}$ with different charge states. However, $\mathrm{N}_{2}, \mathrm{CH}_{4}$ and $\mathrm{H}_{2}$ can only form very weak interactions with $\mathrm{B}_{2} \mathrm{CNTs}$. Therefore, the study demonstrates $\mathrm{B}_{2} \mathrm{CNTs}$ could sever as promising materials for $\mathrm{CO}_{2}$ capture and gas separation.
\end{abstract}

Keywords $\mathrm{CO}_{2}$ capture; Gas separation; Boron carbon nanotubes; Charge states; DFT calculations

\title{
Introduction
}

It is well known that the fast accumulation of $\mathrm{CO}_{2}$ in the atmosphere is the predominant cause of global warming. The atmospheric concentration of $\mathrm{CO}_{2}$ has increased dramatically in the last decades and is expected to continually increase for the next few decades. ${ }^{1}$ Thus, development of new materials and technologies for reducing or eliminating $\mathrm{CO}_{2}$ emission from various industrial processes are of utmost importance. ${ }^{2,3}$ Carbon capture and storage (CCS) technologies are a promising route for mitigating $\mathrm{CO}_{2}$ emissions in the near future, because CCS could provide a mid-term solution allowing humanity to continue using fossil energy until renewable energy technologies mature. ${ }^{4}$ 
Before $\mathrm{CO}_{2}$ can be sequestrated it must be separated and captured from the major sources. Flue gas emissions of power plants are responsible for roughly $33-40 \%$ of total $\mathrm{CO}_{2}$ emissions. ${ }^{5}$ As the major component of the flue gas is nitrogen $(>70 \%)$ and the major impurity is $\mathrm{CO}_{2}(10-15 \%)$, CCS will require the separation of $\mathrm{CO}_{2}$ from nitrogen. Another energy-related separation involving $\mathrm{CO}_{2}$ is removal of $\mathrm{CO}_{2}$ from natural gas. Demand for natural gas is expected to increase continuously in the coming years, because natural gas produces lower $\mathrm{CO}_{2}$ emissions than other fossil fuels. In fact, the demand for natural gas may exceed that for coal by $2020 .^{6}$ Natural gas is mainly composed of methane, typically 80-95\%, with impurities such as $\mathrm{CO}_{2}$, nitrogen, and heavier hydrocarbons, depending on the source of the gas. In addition, methane from landfill gas is a rapidly growing source of natural gas; however, it often contains unacceptable levels of contaminants. A typical municipal or industrial landfill gas consists of approximately $40-60 \% \mathrm{CO}_{2}{ }^{7}$ The separation of $\mathrm{CO}_{2}$ from methane is essential for the upgrading of natural gas and the treatment of landfill gas to improve purity and reduce pipeline corrosion induced by acid $\mathrm{CO}_{2}$ gas. $^{2}$

Generally speaking, three types of gas mixtures that are of the most current interest are targeted for capture technologies, namely, postcombustion (predominantly $\mathrm{CO}_{2} / \mathrm{N}_{2}$ separation), natural gas sweetening $\left(\mathrm{CO}_{2} / \mathrm{CH}_{4}\right)$, and precombustion $\left(\mathrm{CO}_{2} / \mathrm{H}_{2}\right)$ capture. ${ }^{3,8}$ The successful capture of $\mathrm{CO}_{2}$ from these gas mixtures will have the greatest likelihood of significantly reducing $\mathrm{CO}_{2}$ emissions into the atmosphere. For those processes, $\mathrm{CO}_{2}$ is firstly separated from other gases either before or after the combustion stage. In general, four main approaches are considered to be suitable for the separation of $\mathrm{CO}_{2}$ from other light gases: cryogenic distillation, membrane purification, absorption with liquids, and 
adsorption using solids. Among these, the adsorption and separation of $\mathrm{CO}_{2}$ using solid adsorbents have attracted a great deal of attention over the past decade. ${ }^{9}$ However, most of these materials are either difficult to regenerate without significant heating or exhibit poor selectivity, resulting in low productivity and high expense. ${ }^{10,11}$ In recent years, micro-porous metal-organic frameworks (MOFs) and nanomaterials have emerged as new class of solids because of the remarkable tunability of their structures and chemical functionality. ${ }^{12-15}$ Meanwhile, there is growing interest in exploring the electronic structures and thermal properties of some novel metal free carbon-boron mixed nanostructures, ${ }^{16-22}$ because they have a wide variety of applications, such as electronic devices and hydrogen storage. Metal free carbon-boron mixed nanostructures have large surface areas, lightweight and porous, which could be good materials for $\mathrm{CO}_{2}$ capture and gas separation. In this paper, we have a performed comprehensive DFT-D study of $\mathrm{CO}_{2}$, $\mathrm{N}_{2}, \mathrm{CH}_{4}$ and $\mathrm{H}_{2}$ adsorption on carbon-boron $\mathrm{B}_{2} \mathrm{C}$ nanotubes $\left(\mathrm{B}_{2} \mathrm{CNTs}\right)$. Here, our main concerns are followed: can the $\mathrm{B}_{2} \mathrm{CNT}$ s capture $\mathrm{CO}_{2}$ from the ambient atmosphere? And what is the mechanism of the adsorption? Besides, the adsorption of $\mathrm{N}_{2}, \mathrm{CH}_{4}$ and $\mathrm{H}_{2}$ on $\mathrm{B}_{2} \mathrm{CNTs}$ are also investigated to gain information whether $\mathrm{B}_{2} \mathrm{CNTs}$ have high selectiveness for the gas separation.

\section{Computational methods}

The first-principles density functional theory plus dispersion (DFT-D) calculations ${ }^{23,24}$ have been carried out using the DMOL3 module in Materials Studio. ${ }^{25,26}$ The $\mathrm{B}_{2} \mathrm{CNTs}$ are fully optimized in the given symmetry using generalized gradient approximation ${ }^{27}$ treated by the Perdew-Burke-Ernzerhof exchange correlation potential with long rang dispersion 
correction via Grimme's scheme ${ }^{28}$. An all electron double numerical atomic orbital augmented by $d$-polarization functions (DNP) is used as basis set. The self-consistent field (SCF) procedure has been used with a convergence threshold of $10^{-6}$ a.u. on energy and electron density. The direct inversion of the iterative subspace technique developed by Pulay is used with a subspace size 6 to speed up SCF convergence on these nanotubes. ${ }^{29}$ In order to achieve the SCF convergence when the gap between the highest occupied molecular orbital and the lowest unoccupied molecular orbital (HOMO-LUMO) is small, thermal smearing using finite-temperature Fermi function of 0.005 a.u. is used. Geometry optimizations were performed with a convergence threshold of 0.002 a.u. $/ \AA$ on the gradient, $0.005 \AA$ on displacements, and $10^{-5}$ a.u. on the energy. The real-space global cutoff radius is set to be $4.10 \AA$. For $\mathrm{B}_{2} \mathrm{C}$ nanotubes $(6,0)$ and $(0,6)$, a tetragonal supercell with dimension $40 \times 40 \times c \AA^{3}$, where $\mathrm{c}$ is $10.329 \AA$ and $10.164 \AA$ for nanotube $(6,0)$ and $(0,6)$, respectively, in order to avoid interactions with its periodic images. The Brillouin zone is sampled by $1 \times 1 \times 6 \mathrm{k}$-points using the Monkhorst-Pack scheme for the two nanotubes.

The adsorption energy of $\mathrm{CO}_{2}, \mathrm{CH}_{4}$ and $\mathrm{H}_{2}$ on $\mathrm{B}_{2} \mathrm{CNTs}$ are calculated from Eq. 1 .

$E_{a d s}=\left(E_{B 2 C N T}+E_{g a s}\right)-E_{B 2 C N T \_g a s}$

where $E_{B 2 C N T_{-} \text {gas }}$ is the total energy of $\mathrm{B}_{2} \mathrm{CNTs}$ with adsorbed gas, $\mathrm{E}_{\mathrm{B} 2 \mathrm{CNT}}$ is the energy of isolated $\mathrm{B}_{2} \mathrm{CNT}$, and $E_{\text {gas }}$ is the energy of isolated gas molecules, such as $\mathrm{CO}_{2}, \mathrm{~N}_{2}, \mathrm{CH}_{4}$ and $\mathrm{H}_{2}$.

The charge doping is simulated by adding electrons to supercell with a compensating uniform charge background of opposite sign.

The charge densities of $\mathrm{CO}_{2}$ adsorbed on $\mathrm{B}_{2} \mathrm{CNT}$ is calculated from Eq. 2. 
$\rho=\frac{8}{8}$

where $\rho\left(10^{13} \mathrm{~cm}^{-2}\right)$ is the electron density of $\mathrm{B}_{2} \mathrm{CNT}$, Q is the total charge per unit cell and $\mathrm{S}$ is the surface area of $\mathrm{B}_{2} \mathrm{CNT}$. In addition, the surface area can be calculated from Eq. 3.

$\mathrm{S}_{(\mathrm{BNNT})}=2 \pi r \mathrm{C}$

Where $\mathrm{r}$ is radius which is $6.640 \AA$ and $\mathrm{c}$ is length of $\mathrm{B}_{2} \mathrm{CNT}(0,6)$.

Atoms in molecules (AIM) theory has been employed in the study in order to better clarify the adsorption and the nature of the interaction of $\mathrm{CO}_{2}, \mathrm{~N}_{2}, \mathrm{CH}_{4}$ and $\mathrm{H}_{2}$ on $\mathrm{B}_{2} \mathrm{CNTs}$. Based on the optimized structures at DFT-D level, the author calculate the wavefunctions at the B3LYP/6-311+G(d) level of theory, then AIM theory which has been used to successfully determine intermolecular interactions of different systems is used in these systems. ${ }^{30-39}$ In the AIM analyses, ${ }^{40}$ the existence of the interaction is indicated by the presence of a so-called bond critical point (BCP). The strength of the bond can be estimated from the magnitude of the electron density $\left(\rho_{\mathrm{bcp}}\right)$ at the BCP. Similarly, the ring or cage structures are characterized by the existence of a ring critical point $(\mathrm{RCP})$ or cage critical point $(\mathrm{CCP})$. Furthermore, the nature of the molecular interaction can be predicted from the topological parameters at the $\mathrm{BCP}$, such as the Laplacian of electron density $\left(\nabla^{2} \rho_{\mathrm{bcp}}\right)$ and energy density $\left(H_{\mathrm{bcp}}\right)$. Generally, the sign of $\nabla^{2} \rho_{\mathrm{bcp}}$ reveals whether charge is concentrated $\left(\nabla^{2} \rho_{\mathrm{bcp}}<0\right)$ as in covalent bonds (shared interaction) or depleted $\left(\nabla^{2} \rho_{\mathrm{bcp}}>0\right)$ as in ionic bonds, H-bonds, and van der Waals interactions (closed-shell interaction. The topological analysis of the system was carried out via the AIMALL program. ${ }^{40}$ 
The transition state between chemisorption and physisorption of $\mathrm{CO}_{2}$ have been investigated using the complete LST (linear synchronous transit)/QST (quadratic synchronous transit) method $^{41}$ implemented in DMOL3 code. The electron distribution and transfer mechanism are determined using the Mulliken method. ${ }^{42}$

\section{Results and discussions}

It is known that a single-walled carbon nanotube can be viewed as rolled over from a carbon grapheme. The helicity of a carbon nanotube is characterized as a pair of integers (n, m). Likewise, a single-walled $\mathrm{B}_{2} \mathrm{CNT}$ can be characterized as a pair of integers $(\mathrm{n}, \mathrm{m})$. Zeng's group investigated both $(n, 0)$ and $(0, n) B_{2} C N T s$. They found that their electronic properties are very different and the $\mathrm{B}_{2} \mathrm{CNTs}$ may become either a metal or semiconductor. ${ }^{17}$ Researchers also demonstrated that the reaction activities of nanotubes are relevant to their diameters and chiralities. ${ }^{43}$ So in this study, we have performed the calculations of $\mathrm{CO}_{2}, \mathrm{~N}_{2}, \mathrm{CH}_{4}$ and $\mathrm{H}_{2}$ adsorption on $(6,0)$ and $(0,6) \mathrm{B}_{2} \mathrm{CNTs}$. We need to mention that the optimized $\mathrm{B}_{2} \mathrm{C}$ nanotubes are in good agreement with the previous study ${ }^{17}$ which provide reasonable start points for the gases adsorption on these nanotubes. In details, the optimized $\mathrm{B}-\mathrm{B}$ bond lengths of $\mathrm{B}_{2} \mathrm{CNT}(6,0)$ and $\mathrm{B}_{2} \mathrm{CNT}(0,6)$ in this study are $1.668 \AA$ and $1.678 \AA$, respectively, which are very close to Zeng's study with the values of $1.677 \AA$ and $1.682 \AA$ for $\mathrm{B}_{2} \mathrm{CNT}(6,0)$ and $\mathrm{B}_{2} \mathrm{CNT}(0,6)$, respectively. The optimized B-C bond lengths of $\mathrm{B}_{2} \mathrm{CNT}(6,0)$ and $\mathrm{B}_{2} \mathrm{CNT}(0,6)$ in the study are $1.564 \AA$ and $1.565 \AA$, respectively, which are consistent with the values of $1.562 \AA$ and $1.564 \AA$ of $\mathrm{B}_{2} \mathrm{CNT}(6,0)$ and $\mathrm{B}_{2} \mathrm{CNT}(0,6)$ of the previous report. ${ }^{17}$ The purpose of this study is to provide useful information that whether these $\mathrm{B}_{2} \mathrm{CNTs}$ can be used as new materials for $\mathrm{CO}_{2}$ capture and gas separation. 


\section{$\mathrm{CO}_{2}, \mathrm{~N}_{2}, \mathrm{CH}_{4}$ and $\mathrm{H}_{2}$ adsorption on $\mathrm{B}_{2} \mathrm{CNT}(6,0)$}

In this part, we start with the discussion of the DFT-D calculational results of the four gases adsorption on $\mathrm{B}_{2} \mathrm{CNTs}(6,0)$ of its neutral charge state. For the reactants of the reactions, $\mathrm{CO}_{2}$ molecule in gas phase, the calculated $\mathrm{C}=\mathrm{O}$ bond lengths are $1.176 \AA$, with $\mathrm{O}=\mathrm{C}=\mathrm{O}$ angle of $180.0^{\circ}$. For $\mathrm{CH}_{4}$ molecule in gas phase, the calculated $\mathrm{C}-\mathrm{H}$ bond lengths are $1.098 \AA$, with $\mathrm{H}-\mathrm{C}-\mathrm{H}$ angles of $109.4^{\circ}$. As to $\mathrm{N}_{2}$ and $\mathrm{H}_{2}$ in gas phase, the calculated $\mathrm{N} \equiv \mathrm{N}$ and $\mathrm{H}-\mathrm{H}$ bond lengths are 1.109 and $0.788 \AA$, respectively. The minimum energy configurations of $\mathrm{CO}_{2}, \mathrm{~N}_{2}, \mathrm{CH}_{4}$ and $\mathrm{H}_{2}$ adsorption on $\mathrm{B}_{2} \mathrm{CNT}(6,0)$ are shown in Figure 1. The calculated geometrical parameters and adsorption energies of these configurations are summarized in Table 1 . Here we will firstly discuss the reaction mechanism of $\mathrm{CO}_{2}$ adsorption on $\mathrm{B}_{2} \mathrm{CNT}(6,0)$. The computed minimum energy path of $\mathrm{CO}_{2}$ adsorption on $\mathrm{B}_{2} \mathrm{CNT}(6,0)$ is showed in Figure 2. In the physisorption configuration (Figure 2) of $\mathrm{CO}_{2}$ adsorption on $\mathrm{B}_{2} \mathrm{CNT}(6,0)$, the distance of one boron atom of $\mathrm{B}_{2} \mathrm{CNT}(6,0)$ and the carbon atom of $\mathrm{CO}_{2}$ molecule is $3.259 \AA$. The long distance between $\mathrm{CO}_{2}$ and $\mathrm{B}_{2} \mathrm{CNT}$ indicates that the interaction of the physisorption configuration is very weak and their interaction is mainly come from the van der Waals force. The adsorption energy of the physisorption configuration is calculated to be 0.15 $\mathrm{eV}$ also support the weak interaction. Because of the weak interaction, the physisorbed $\mathrm{CO}_{2}$ molecule almost did not undergo noticeable structural changes compared with the geometry of gas phase $\mathrm{CO}_{2}$. The linear $\mathrm{CO}_{2}$ molecule is attached to $\mathrm{B}_{2} \mathrm{C}$ paralleled to $\mathrm{B}$ $\mathrm{B}$ bond. The $\mathrm{O}-\mathrm{C}-\mathrm{O}$ angle is $179.8^{\circ}$. In addition, the charge transfer from $\mathrm{B}_{2} \mathrm{CNT}(6,0)$ to $\mathrm{CO}_{2}$ is negligible with the value of only $0.002 \mathrm{e}^{-}$. The molecular graphs of the four gases adsorption on $\mathrm{B}_{2} \mathrm{CNT}$ are displayed in Figure 4. From Figure 4 (a) we can see that 
the interaction between $\mathrm{CO}_{2}$ and $\mathrm{B}_{2} \mathrm{CNT}(6,0)$ can be confirmed by the existence of the bond critical point $(\mathrm{BCP})$ of the $\mathrm{O}-\mathrm{B}$ contact. The calculated topological parameters at the BCPs of the $\mathrm{B}_{2} \mathrm{CNT}$ gases are listed in Table $\mathrm{S} 2$ in supporting information. Obviously, the electron densities of the physisorption configuration at the BCPs of the bonds between $\mathrm{CO}_{2}$ and $\mathrm{B}_{2} \mathrm{CNT}(6,0)$ are small (Table S2), which supports that interaction between them is weak. Furthermore, our calculations indicate the physisorption process has no transition state.

In its chemisorbed configuration (Figure 1 (a)), the $\mathrm{CO}_{2}$ molecule undergoes structural distortion to a bent geometry and double-bond breaking of one $\mathrm{C}=\mathrm{O}$ bond. The $\mathrm{O}-\mathrm{C}-\mathrm{O}$ bond angle is $122.4^{\circ}$, and the broken $\mathrm{C}-\mathrm{O}$ bond is significantly elongated to $1.391 \AA$ on top of the B. The B-B site is considerably pulled out and enlonged by $0.659 \AA$. The distances of $\mathrm{B}-\mathrm{C}$ and $\mathrm{B}-\mathrm{O}$ bond are $1.596 \AA$ and $1.422 \AA$, respectively, forming a $\mathrm{C}-\mathrm{O}-$ B-B four-member ring for chemisorbed $\mathrm{CO}_{2}$ on $\mathrm{B}_{2} \mathrm{CNT}(6,0)$. The chemisorption energy is calculated to be $0.60 \mathrm{eV}$ at the DFT-D level. Along with the fact that $0.37 \mathrm{e}^{-}$charge transfers from $\mathrm{B}_{2} \mathrm{CNT}(6,0)$ to $\mathrm{CO}_{2}$ by Mulliken population analysis, strong interaction between the two moieties is verified and hence the large chemisorption energy. The calculated adsorption of this mode demonstrates that the reaction is a thermally favourable process. Moreover, we also performed LST/QST calculation to indentify the transition state from the physisorption to chemisorption configurations. As shown in Table S2, the electron densities at the BCPs for the O1-B bonds of physisorption (Figure 4(a)), transition state (Figure 4(b)), and chemisorption (Figure 4(c)) increase gradually, which is consistently with the adsorption process starts from weak to strong interaction as well as the O1-B bond distances decrease with the values from $3.291 \AA$ to $1.828 \AA$ and 
then $1.422 \AA$ for the three structures, respectively. Our results show the chemisorption process has a barrier of $0.75 \mathrm{eV}$, from its physisorption configuration. The low barrier indicates the reaction is energetically favourable process. The strong interaction of the chemisorption and low barrier of the reaction from physisorption to chemisorption indicate $\mathrm{B}_{2} \mathrm{CNT}(6,0)$ can serve as a good material for $\mathrm{CO}_{2}$ capture.

The adsorptions of $\mathrm{N}_{2}, \mathrm{CH}_{4}$ and $\mathrm{H}_{2}$ on $\mathrm{B}_{2} \mathrm{CNT}(6,0)$ are also calculated for comparisons. We found that $\mathrm{N}_{2}, \mathrm{CH}_{4}$ and $\mathrm{H}_{2}$ are on physisorbed under all conditions. Table 1 lists the important bond distances and adsorption energies of $\mathrm{N}_{2}, \mathrm{CH}_{4}$ and $\mathrm{H}_{2}$ adsorption on $\mathrm{B}_{2} \mathrm{CNT}(6,0)$. The N...B distance of $\mathrm{N}_{2}$ on the adsorbent is $3.195 \AA$, The C...B distance of $\mathrm{CH}_{4}$ on the adsorbent is $3.524 \AA$, and $\mathrm{H}$... B distance of $\mathrm{H}_{2}$ on the adsorbent is $2.734 \AA$. Table 1 gives a summary of adsorption energies of $\mathrm{N}_{2}, \mathrm{CH}_{4}$ and $\mathrm{H}_{2}$ on $\mathrm{B}_{2} \mathrm{CNT}(6,0)$. The adsorption energies are $0.09,0.13$ and $0.07 \mathrm{eV}$ for $\mathrm{N}_{2}, \mathrm{CH}_{4}$ and $\mathrm{H}_{2}$ on $\mathrm{B}_{2} \mathrm{CNT}(6,0)$, respectively, which are consistently with small values of electron densities (Table S2) at the BCPs of the bonds between $\mathrm{N}_{2}, \mathrm{CH}_{4}, \mathrm{H}_{2}$ and $\mathrm{B}_{2} \mathrm{CNT}(6,0)$. However, $\mathrm{CO}_{2}$ can interact with $\mathrm{B}_{2} \mathrm{CNT}(6,0)$ strongly with chemisorption configuration and the adsorption energy is $0.60 \mathrm{eV}$, which is also supported by the large electron densities at the BCPs for the $\mathrm{O} 1-\mathrm{B}$ bond of the configuration. The big differences of the adsorption energies on $\mathrm{B}_{2} \mathrm{CNT}(6,0)$ between $\mathrm{CO}_{2}$ and $\mathrm{N}_{2}, \mathrm{CH}_{4}, \mathrm{H}_{2}$ indicate $\mathrm{B}_{2} \mathrm{CNT}(6,0)$ can serve as a good candidate for gas separation. In all, our calculational results demonstrate $\mathrm{B}_{2} \mathrm{CNT}(6,0)$ could be a good material for $\mathrm{CO}_{2}$ capture and gas separation based on its high reactivity. However, the synthesis of $\mathrm{B}_{2} \mathrm{CNT}(6,0)$ is very difficult because it is highly strained. ${ }^{17}$

\section{$\mathrm{CO}_{2}, \mathrm{~N}_{2}, \mathrm{CH}_{4}$ and $\mathrm{H}_{2}$ adsorption on $\mathrm{B}_{2} \mathrm{CNT}(0,6)$}


For $\mathrm{CO}_{2}, \mathrm{~N}_{2}, \mathrm{CH}_{4}$ and $\mathrm{H}_{2}$ adsorption on $\mathrm{B}_{2} \mathrm{CNT}(0,6)$ on its neutral charge state, the calculated geometrical parameters and adsorption energies of physisorbed and/or chemisorbed gases on a $\mathrm{B}_{2} \mathrm{CNT}(0,6)$ are summarized in Table $\mathrm{S} 1$ in supporting information. In the physisorbed configuration of $\mathrm{CO}_{2}$ on $\mathrm{B}_{2} \mathrm{CNT}(0,6)$, the adsorption energy is calculated to be $0.10 \mathrm{eV}$, and the physisorption is controlled by typical dispersion forces. The charge transfer between $\mathrm{B}_{2} \mathrm{CNT}(0,6)$ and $\mathrm{CO}_{2}$ molecule is negligible. Similar to the physisorption configuration of $\mathrm{CO}_{2}$ adsorption $\mathrm{B}_{2} \mathrm{CNT}(6,0)$, the $\mathrm{CO}_{2}$ molecule sits quite far from $\mathrm{B}_{2} \mathrm{CNT}(0,6)$ and the $\mathrm{B} \ldots \mathrm{C}$ distance is $3.259 \AA$, and the physisorbed $\mathrm{CO}_{2}$ molecule almost did not undergo noticeable structural changes compared with the geometry of gas phase $\mathrm{CO}_{2}$. For the chemisorption of $\mathrm{CO}_{2}$ on $\mathrm{B}_{2} \mathrm{CNT}$ $(0,6)$, the $\mathrm{CO}_{2}$ molecule bonds with $\mathrm{B}_{2} \mathrm{CNT}$ and the chemisorption energy is calculated to be $0.27 \mathrm{eV}$ in the DFT-D level. For this chemisorbed configuration, the $\mathrm{B}-\mathrm{C}$ and $\mathrm{B}-\mathrm{O}$ distances are $1.588 \AA$ and $1.396 \AA$, respectively. Moreover, we also performed LST/QST calculation for indentified the transition state between the physisorption to chemisorption configurations. Our results show the chemisorption process had a barrier of $1.18 \mathrm{eV}$, from the physisorption configuration. The high barrier indicates the reaction is not feasible compared with that $\mathrm{CO}_{2}$ adsorption on $\mathrm{B}_{2} \mathrm{CNT}(6,0)$.

Moreover, we also performed the calculations of $\mathrm{N}_{2}, \mathrm{CH}_{4}$ and $\mathrm{H}_{2}$ adsorption on $\mathrm{B}_{2} \mathrm{CNT}$ $(0,6)$ for comparison. The calculational results show the three gases adsorption on $\mathrm{B}_{2} \mathrm{CNT}(0,6)$ are on physisorption configurations. Figure 3 and Table 2 list the important bond distances and adsorption energies of the configurations. The three gases are sitting quite far from the nanotube. In detail, the N...B distance of $\mathrm{N}_{2}$ on the adsorbent is 3.120 $\AA$, the $\mathrm{C}$...B distance of $\mathrm{CH}_{4}$ on the adsorbent is $3.474 \AA$, and $\mathrm{H} . . . \mathrm{B}$ distance of $\mathrm{H}_{2}$ on 
the adsorbent is $2.664 \AA$. Obviously, the electron densities at the BCPs of the bonds between $\mathrm{N}_{2}, \mathrm{CH}_{4}, \mathrm{H}_{2}$ and $\mathrm{B}_{2} \mathrm{CNT}(0,6)$ are small (Table 4), which is consistent with the interactions between them are very weak and the calculated adsorption energies are 0.10 , 0.15 and $0.07 \mathrm{eV}$ for $\mathrm{N}_{2}, \mathrm{CH}_{4}$ and $\mathrm{H}_{2}$ on $\mathrm{B}_{2} \mathrm{CNT}(0,6)$, respectively. Although, $\mathrm{CO}_{2}$ molecule can form relatively strong interaction with $\mathrm{B}_{2} \mathrm{CNT}(0,6)$, the difference of the adsorption energy of $\mathrm{CO}_{2}$ on $\mathrm{B}_{2} \mathrm{CNT}(0,6)$ (with the value of $0.27 \mathrm{eV}$ ) is only slight bigger than those of the other three gases. Moreover, the barrier from physisorption to chemisorption is quite high for $\mathrm{CO}_{2}$ on $\mathrm{B}_{2} \mathrm{CNT}(0,6)$. So $\mathrm{B}_{2} \mathrm{CNT}(0,6)$ on its neutral state is not feasible for $\mathrm{CO}_{2}$ capture and gas separation.

\section{$\mathrm{CO}_{2}, \mathrm{~N}_{2}, \mathrm{CH}_{4}$ and $\mathrm{H}_{2}$ adsorption on $\mathrm{B}_{2} \mathrm{CNT}$ with charged states}

In the previous part we have investigated $\mathrm{CO}_{2}, \mathrm{~N}_{2}, \mathrm{CH}_{4}$ and $\mathrm{H}_{2}$ adsorption on $\mathrm{B}_{2} \mathrm{CNT}$ (6, $0)$ and $\mathrm{B}_{2} \mathrm{CNT}(0,6)$ with their neutral charge state. The adsorption energies of $\mathrm{CO}_{2}$ chemisorbed on $\mathrm{B}_{2} \mathrm{CNT}(6,0)$ and $\mathrm{B}_{2} \mathrm{CNT}(0,6)$ with their neutral state are $0.60 \mathrm{eV}$ and $0.27 \mathrm{eV}$, respectively. By comparing the Mulliken atomic charges of the two nanotubes before and after $\mathrm{CO}_{2}$ adsorption on them with their neutral state, we find that the charge transfer from the two boron atoms which directly connect with $\mathrm{CO}_{2}$ molecules of the two chemisorbed configurations, $\mathrm{CO}_{2}$ adsorption on $\mathrm{B}_{2} \mathrm{CNT}(6,0)$ and $\mathrm{B}_{2} \mathrm{CNT}(0,6)$, are $0.017 \mathrm{e}$ and $0.042 \mathrm{e}$, respectively, and the charge transfer from the two nanotubes to $\mathrm{CO}_{2}$ molecules are $-0.347 \mathrm{e}$ and $-0.384 \mathrm{e}$, respectively, which mean that the charge transfer from the two nanotubes to $\mathrm{CO}_{2}$ molecules are not mainly come from the two boron atoms which directly connect with $\mathrm{CO}_{2}$ molecules, but from the other atoms of the two nanotubes via the bridges of the two boron atoms. The mechanism of charged transfer from two nanotubes to $\mathrm{CO}_{2}$ molecules is similar to Yang's report of $\mathrm{O}_{2}$ adsorption on 
boron-doped carbon nanotube, in which the negative charges of carbon atoms transfer to $\mathrm{O}_{2}$ via the bridge of boron atom. ${ }^{44}$ Although the chemical compositions of the two nanotubes are same, the chemisorbed configurations of $\mathrm{CO}_{2}$ adsorption on the two nanotubes and the charge transfer mechanism between $\mathrm{CO}_{2}$ and the two nanotubes are similar, our calculational results indicate that $\mathrm{CO}_{2}$ adsorption on $\mathrm{B}_{2} \mathrm{CNT}(6,0)$ is more favorable than adsorption on $\mathrm{B}_{2} \mathrm{CNT}(0,6)$. The reason could be that the diameters of $\mathrm{B}_{2} \mathrm{CNT}(6,0)$ with the value of $5.0 \AA$ is smaller than that $\mathrm{B}_{2} \mathrm{CNT}(0,6)$ with the value of $6.5 \AA$, which is in a good agreement with the previous study of that the nanotube with small size of diameter is more active than that of with large diameter. ${ }^{43}$ In all, the calculational results indicate that $\mathrm{B}_{2} \mathrm{CNT}(6,0)$ with its neutral state can serve as a good material for $\mathrm{CO}_{2}$ capture and gas separation while the $\mathrm{B}_{2} \mathrm{CNT}(0,6)$ cannot.

As we know that $\mathrm{CO}_{2}$ is Lewis acid and it prefers to gain electron pair in its reaction. With electron ejection to the $\mathrm{B}_{2} \mathrm{CNT}$, the interaction between $\mathrm{CO}_{2}$ and $\mathrm{B}_{2} \mathrm{CNT}$ might be enhanced. In order to prove the above analysis, we firstly performed the calculations of $\mathrm{B}_{2} \mathrm{CNT}(0,6)$ with $1 \mathrm{e}^{-}$and $2 \mathrm{e}^{-}$charge states. The Mulliken charge analysis for neutral, $1 \mathrm{e}^{-}$ and $2 \mathrm{e}^{-}$charge states of $\mathrm{B}_{2} \mathrm{CNT}(0,6)$ are in Table 3 . We can see that for the neutral, $1 \mathrm{e}^{-}$ and $2 \mathrm{e}^{-}$charge states of $\mathrm{B}_{2} \mathrm{CNT}(0,6)$, the Mulliken atomic charges of $\mathrm{C}$ atoms are $0.289 \mathrm{e},-0.295 \mathrm{e}$, and $0.299 \mathrm{e}$, respectively. It means that the charge distributions of $\mathrm{C}$ atoms in $\mathrm{B}_{2} \mathrm{CNT}(0,6)$ can't be influenced significantly by the total charges of $\mathrm{B}_{2} \mathrm{CNT}(0$, 6). However, there is obvious change of charge distributions of B atoms with the three charge states, and the atomic charges of B atoms are $+0.144 \mathrm{e},+0.126 \mathrm{e}$ and $+0.108 \mathrm{e}$ for the neutral, $1 \mathrm{e}^{-}$and $2 \mathrm{e}^{-}$charge states of $\mathrm{B}_{2} \mathrm{CNT}(0,6)$, respectively. It means that the negative charges are mostly applied on the $\mathrm{B}$ atoms of $\mathrm{B}_{2} \mathrm{CNT}(0,6)$. The more negative 
charge distributions on $\mathrm{B}$ atoms of $\mathrm{B}_{2} \mathrm{CNT}$, the easier for $\mathrm{CO}_{2}$ gain electron from $\mathrm{B}_{2} \mathrm{CNT}$, and the stronger interaction can be formed between $\mathrm{CO}_{2}$ and the adsorbent. Base on the analysis above, the negative charged $\mathrm{B}_{2} \mathrm{CNT}$ can form strong interactions with $\mathrm{CO}_{2}$, which means that the ability of $\mathrm{CO}_{2}$ capture of the adsorbent can be enhanced by the injection of negative charges. In order to investigate whether the ability of $\mathrm{CO}_{2}$ capture and gas separation of $\mathrm{B}_{2} \mathrm{CNT}(0,6)$ can be enhanced by injection of extra electrons or not, we have performed calculations of $\mathrm{CO}_{2}, \mathrm{~N}_{2}, \mathrm{CH}_{4}$ and $\mathrm{H}_{2}$ adsorption $1 \mathrm{e}^{-}$and $2 \mathrm{e}^{-}$charge states of $\mathrm{B}_{2} \mathrm{CNT}(0,6)$. We start with the analysis of the physisorbed configurations of $\mathrm{CO}_{2}$ adsorption on $\mathrm{B}_{2} \mathrm{CNT}(0,6)$ with $0 \mathrm{e}, 1 \mathrm{e}^{-}$and $2 \mathrm{e}^{-}$charge states. We can see that the adsorption energies of $\mathrm{CO}_{2}$ physically adsorbed on $\mathrm{B}_{2} \mathrm{CNT}(0,6)$ with $0,1 \mathrm{e}^{-}$and $2 \mathrm{e}^{-}$ charge states are around $0.14 \sim 0.19 \mathrm{eV}$, and the values of charge transfer between $\mathrm{CO}_{2}$ and the different charged $\mathrm{B}_{2} \mathrm{CNT}(0,6)$ are negligible, which mean that the charge states of $\mathrm{B}_{2} \mathrm{CNT}(0,6)$ don't have significant effect on the physisorbed configurations of $\mathrm{CO}_{2}$ adsorption on the nanotubes. The following is the analysis of the chemisorbed configurations of $\mathrm{CO}_{2}$ adsorption on the nanotube. By injection one electron and two electrons to the $\mathrm{B}_{2} \mathrm{CNT}(0,6), \mathrm{CO}_{2}$ molecule forms strong interaction with $\mathrm{B}_{2} \mathrm{CNT}(0,6)$ with adsorption energy of 0.48 and $0.78 \mathrm{eV}$, respectively, while the value is $0.27 \mathrm{eV}$ with its neutral state. We can see from Table 2 that adsorption energies of $\mathrm{CO}_{2}$ on $\mathrm{B}_{2} \mathrm{CNT}(0,6)$ increase with negative charges, while the bond distances of B-O1 and B-C increase with the negative charges. Here want to mention that the configuration changes, with decomposition and reconstruction of the two molecules, $\mathrm{CO}_{2}$ and $\mathrm{B}_{2} \mathrm{CNT}(0,6)$, have comprehensive effects on the structures of $\mathrm{B}_{2} \mathrm{CNT}(0,6) \mathrm{CO}_{2}$ with different charge states. We can see that the $\mathrm{C}-\mathrm{O} 1$ bond in gas phase $\mathrm{CO}_{2}$ is $1.176 \AA$, while $\mathrm{C}-\mathrm{O} 1$ bonds in the 
$\mathrm{B}_{2} \mathrm{CNT}(0,6) \mathrm{CO}_{2}$ configurations with $0,1 \mathrm{e}^{-}$and $2 \mathrm{e}^{-}$charge states were elongated to 1.391 $\AA, 1.380 \AA$, and $1.371 \AA$, respectively. Meanwhile, the B-B distance in $\mathrm{B}_{2} \mathrm{CNT}(0,6)$ with neutral state is $1.678 \AA$, however, after $\mathrm{CO}_{2}$ adsorption on it, the adsorption site of $\mathrm{B} \ldots \mathrm{B}$ bonds were elongated to $2.899 \AA, 2.904 \AA$, and $2.917 \AA$, with $0,1 \mathrm{e}^{-}$and $2 \mathrm{e}^{-}$charge states, respectively. The results show that the adsorption site of $\mathrm{B} \ldots \mathrm{B}$ bond in $\mathrm{B}_{2} \mathrm{CNT}(0,6) \mathrm{CO}_{2}$ configurations with negative charge states were pulled out more obviously than that of the bond with neutral charge state, which indicates the interactions between $\mathrm{CO}_{2}$ and negative charged $\mathrm{B}_{2} \mathrm{CNT}(0,6)$ are stronger than that of the neutral one. The charge transfer from $1 \mathrm{e}^{-}$and $2 \mathrm{e}^{-}$charge states of $\mathrm{B}_{2} \mathrm{CNT}(0,6)$ to $\mathrm{CO}_{2}$ molecules also increase, and the values of charge transfer from $1 \mathrm{e}^{-}$and $2 \mathrm{e}^{-}$charge states of $\mathrm{B}_{2} \mathrm{CNT}(0,6)$ to $\mathrm{CO}_{2}$ molecules are $0.448 \mathrm{e}^{-}$and $0.512 \mathrm{e}^{-}$, respectively, while the value is $0.383 \mathrm{e}^{-}$with its neutral state. Researches summary the criteria of the good performance adsorbents of $\mathrm{CO}_{2}$ capture, and one of the important criterion is that the adsorption energies of $\mathrm{CO}_{2}$ on these adsorbents should be among $0.5 \sim 1.0 \mathrm{eV} .{ }^{45}$ According to the criterion, we can see that $\mathrm{B}_{2} \mathrm{CNT}(0,6)$ with two negative charges could be a good adsorbent for $\mathrm{CO}_{2}$ capture.

The adsorptions of $\mathrm{N}_{2}, \mathrm{CH}_{4}$ and $\mathrm{H}_{2}$ on $\mathrm{B}_{2} \mathrm{CNT}(0,6)$ with different charge carrying states are also calculated for comparisons. We found $\mathrm{N}_{2}, \mathrm{CH}_{4}$ and $\mathrm{H}_{2}$ are on physisorbed under all conditions. Table 2 lists the important bond distances, adsorption energies and electron transfer from $\mathrm{B}_{2} \mathrm{CNT}(0,6)$ to $\mathrm{N}_{2}, \mathrm{CH}_{4}$ and $\mathrm{H}_{2}$ for the three gases adsorption on $\mathrm{B}_{2} \mathrm{CNT}(0,6)$ with different charge carrying states. We can see that in all the conditions of neutral, $1 \mathrm{e}^{-}$and $2 \mathrm{e}^{-}$charge states of $\mathrm{B}_{2} \mathrm{CNT}(0,6)$, the distances between $\mathrm{N}_{2}, \mathrm{CH}_{4}, \mathrm{H}_{2}$ and adsorbents are quite far. The N...B distances of $\mathrm{N}_{2}$ molecules on the adsorbents are among $3.1 \sim 3.2 \AA$. The $\mathrm{C}$... B distances of $\mathrm{CH}_{4}$ molecules on the adsorbents are $\sim 3.5 \AA$ 
and $\mathrm{H}$... B distances of $\mathrm{H}_{2}$ on the adsorbents are $\sim 2.7 \AA$. Figure 5 gives a summary of adsorption energies of $\mathrm{CO}_{2}, \mathrm{~N}_{2}, \mathrm{CH}_{4}$ and $\mathrm{H}_{2}$ on $\mathrm{B}_{2} \mathrm{CNT}(0,6)$ with neutral, $1 \mathrm{e}^{-}$and $2 \mathrm{e}^{-}$ charge states. We can see from the Figure 5 that, for the three charge carrying states of $\mathrm{B}_{2} \mathrm{CNT}(0,6)$, the interactions between $\mathrm{N}_{2}, \mathrm{CH}_{4}, \mathrm{H}_{2}$ and $\mathrm{B}_{2} \mathrm{CNT}(0,6)$ are very weak and the adsorption energies are around $0.10 \sim 0.14 \mathrm{eV}$ for $\mathrm{N}_{2}, 0.15 \sim 0.17 \mathrm{eV}$ for $\mathrm{CH}_{4}$ and $0.08 \sim 0.10 \mathrm{eV}$ for $\mathrm{H}_{2}$, respectively. It means that when the system was injected with one electron and two electrons, the configurations of $\mathrm{N}_{2}, \mathrm{CH}_{4}$ and $\mathrm{H}_{2}$ on the $\mathrm{B}_{2} \mathrm{CNT}(0,6)$ remain physisorption, and the change of adsorption energy is negligible compared with those of on neutral state of $\mathrm{B}_{2} \mathrm{CNT}(0,6)$. However, with one electron and two electrons systems, the interaction between $\mathrm{CO}_{2}$ and $\mathrm{B}_{2} \mathrm{CNT}(0,6)$ become stronger and the adsorption energies are 0.48 and $0.76 \mathrm{eV}$ for $\mathrm{CO}_{2}$ on $1 \mathrm{e}^{-}$and $2 \mathrm{e}^{-}$charge states of $\mathrm{B}_{2} \mathrm{CNT}$, respectively. In order to know the charge effect on the gases adsorption on $\mathrm{B}_{2} \mathrm{CNT}(6,0)$, we have performed the calculations of the four gases adsorption on negative charged $\mathrm{B}_{2} \mathrm{CNT}(6,0)$. Our calculational results show that the adsorption energies of $\mathrm{CO}_{2}, \mathrm{~N}_{2}, \mathrm{CH}_{4}$ and $\mathrm{H}_{2}$ adsorption on $2 \mathrm{e}^{-}$charged state of $\mathrm{B}_{2} \mathrm{CNT}(6,0)$ are $0.71,0.12,0.14$ and $0.07 \mathrm{eV}$, respectively. Similar to the charged effect on the adsorption energies of $\mathrm{B}_{2} \mathrm{CNT}(0,6)$, the calculational results show the adsorption energy of $\mathrm{CO}_{2}$ on negative charged $\mathrm{B}_{2} \mathrm{CNT}(6,0)$ increased, and the other three gases, $\mathrm{N}_{2}, \mathrm{CH}_{4}$ and $\mathrm{H}_{2}$, are still weakly bonded with $\mathrm{B}_{2} \mathrm{CN}(6,0)$ and not insensitive to the charges on the tube. We need to point out that the reason of that $\mathrm{CO}_{2}$ is strongly bonded with negative charged $\mathrm{B}_{2} \mathrm{CNT}$ and sensitive to charge state of the adsorbent while the other three gases are not is that $\mathrm{CO}_{2}$ is a quadrupole molecule and has larger quadrupole moment than that of $\mathrm{N}_{2}$, while $\mathrm{CH}_{4}, \mathrm{H}_{2}$ are nonpolar. The quadrupole moments of $\mathrm{CO}_{2}$ and $\mathrm{N}_{2}$ are $13.4 \times 10^{-40} \mathrm{Cm}^{2}$ and $4.7 \times 10^{-40}$ 
$\mathrm{Cm}^{2}$, respectively. ${ }^{3}$ Generally speaking, the molecule with larger dipole moment is likely more sensitive to charges than those of with smaller dipole moments or the nonpolar molecules, such as $\mathrm{CH}_{4}$ and $\mathrm{H}_{2}$. In a word, from the study we can see that negative charged $\mathrm{B}_{2} \mathrm{CNT}$ s have very high selectiveness for the capture $\mathrm{CO}_{2}$ from $\mathrm{N}_{2}, \mathrm{CH}_{4}$ and $\mathrm{H}_{2}$ mixtures. Therefore, we can draw a conclusion that negative charged $\mathrm{B}_{2} \mathrm{CNT}(0,6)$ can serve as a good candidate for $\mathrm{CO}_{2}$ capture and gas separation. Here we need to mention that the extra electron injection can be easily realized experimentally using electrochemical methods, electrospray, electron beam or gate voltage control. ${ }^{46,47}$ The calculated charge densities of $\mathrm{B}_{2} \mathrm{CNT}(0,6)$ with $2 \mathrm{e}^{-}$charge state is $9.45 \times 10^{13} \mathrm{~cm}^{-2}$ and the charge density with the order of $10^{13} \mathrm{~cm}^{-2}$ can be easily achieved. For example, a charge density of $7.4 \times 10^{13} \mathrm{~cm}^{-2}$ has been obtained with the most common gate. ${ }^{46}$ The further investigations about the reaction activities dependences of the nanotubes with the increasing of diameters of $\mathrm{B}_{2} \mathrm{CNT}$ and coverage of the gases as well as adsorption mechanisms of the gases allocated inside of nanotubes could also be very interesting. Here we need to point out that the $\mathrm{B}_{2} \mathrm{C}$ nanotubes in this study haven't been synthesized yet. However, many boron carbon materials and boron doped carbon nanotubes have been successfully synthesized and reported..$^{44,48-50}$ So that the nanotubes in this study could in principle be synthesized, especially for $\mathrm{B}_{2} \mathrm{CNT}(0, \mathrm{n})$ based on their low strain energies. ${ }^{17}$

\section{Conclusions}

In summary, we have performed DFT-D calculations to investigate the reaction mechanisms of $\mathrm{CO}_{2}, \mathrm{~N}_{2}, \mathrm{CH}_{4}$ and $\mathrm{H}_{2}$ adsorption on $\mathrm{B}_{2} \mathrm{CNTs}$. Our calculational results 
show that $\mathrm{B}_{2} \mathrm{CNT}(6,0)$ can serve as a good material for $\mathrm{CO}_{2}$ capture and gas separation. For the relative big diameter $\mathrm{B}_{2} \mathrm{CNT}(0,6)$, the abilities of $\mathrm{CO}_{2}$ capture and gas separation can be enhanced by injection with negative charges. The study demonstrates not only $\mathrm{B}_{2} \mathrm{CNTs}$ could sever as promising materials for $\mathrm{CO}_{2}$ capture and gas separation but also injection with negative charge to the materials can enhance their ability for these functions

\section{Acknowledgements}

Q. S. acknowledges financial support from Early Career Researcher grant of The University of Queensland. A.D. greatly appreciates financial support of the Australian Research Council QEII Fellowship. We also acknowledge generous grants of high performance computer time from both The University of Queensland and the National Computational Infrastructure (NCI). 


\section{Captions}

Figure 1. The configurations of $\mathrm{CO}_{2}, \mathrm{CH}_{4}, \mathrm{~N}_{2}$ and $\mathrm{H}_{2}$ adsorption on $\mathrm{B}_{2} \mathrm{CNT}(6,0)$. Atom color code: pink, boron; gray, carbon; blue, nitrogen; red oxygen; light gray, hydrogen.

Figure 2. Computed minimum energy path of $\mathrm{CO}_{2}$ adsorption on $\mathrm{B}_{2} \mathrm{CNT}(6,0)$ nanotube (top and side view of two adsorptions and transition state). Atom color code: same to those in Figure 1.

Figure 3. The configurations of $\mathrm{CO}_{2}, \mathrm{CH}_{4}, \mathrm{~N}_{2}$ and $\mathrm{H}_{2}$ adsorption on $\mathrm{B}_{2} \mathrm{CNT}(0,6)$. Atom color code: same to those in Figure 1.

Figure 4. The molecular graphs of the intermediates and transition state of $\mathrm{CO}_{2}, \mathrm{CH}_{4}, \mathrm{~N}_{2}$ and $\mathrm{H}_{2}$ adsorption on $\mathrm{B}_{2} \mathrm{CNT}$, where the bond critical points (BCPs), ring critical points (RCPs) and cage critical point (CCP) are denoted as small green, red and blue dots, respectively.

Figure 5. Adsorption energies $(\mathrm{eV})$ of $\mathrm{CO}_{2}, \mathrm{~N}_{2}, \mathrm{CH}_{4}$ and $\mathrm{H}_{2}$ adsorption on $\mathrm{B}_{2} \mathrm{CNT}(0,6)$ with neutral, $1 \mathrm{e}^{-}$and $2 \mathrm{e}^{-}$charge states systems.

Table 1. Adsorption energy in $\mathrm{eV}$, bond distance (r) in $\AA$ and bond angle $(\alpha)$ in deg of $\mathrm{CO}_{2}, \mathrm{CH}_{4}$ and $\mathrm{N}_{2}$ adsorption on $\mathrm{B}_{2} \mathrm{CNT}(6,0)$.

Table 2. Adsorption energy in $\mathrm{eV}$, bond distance (r) in $\AA$ and bond angle ( $\alpha$ ) in deg of $\mathrm{CO}_{2}, \mathrm{CH}_{4}, \mathrm{~N}_{2}$ and $\mathrm{H}_{2}$ adsorption on $\mathrm{B}_{2} \mathrm{CNT}(0,6)$ with different charge states.

Table 3. Mulliken change distribution of configurations of $\mathrm{CO}_{2}, \mathrm{CH}_{4}, \mathrm{~N}_{2}$ and $\mathrm{H}_{2}$ adsorption on $\mathrm{B}_{2} \mathrm{CNTs}$ and charge transfer $(\mathrm{CT})$ from $\mathrm{B}_{2} \mathrm{CNTs}$ to the gases of the configurations. 


\section{References}

(1) Keith, D. W. Science 2009, 325, 1654.

(2) Bae, Y.-S.; Snurr, R. Q. Angew. Chem. Int. Ed. 2011, 50, 11586.

(3) D'Alessandro, D. M.; Smit, B.; Long, J. R. Angew. Chem. Int. Ed. 2010, 49, 6058.

(4) Haszeldine, R. S. Science 2009, 325, 1647.

(5) Yang, H.; Xu, Z.; Fan, M.; Gupta, R.; Slimane, R. B.; Bland, A. E.; Wright, I. J. Environ. Sci. 2008, 20, 14.

(6) Tagliabue, M.; Farrusseng, D.; Valencia, S.; Aguado, S.; Ravon, U.; Rizzo, C.; Corma, A.; Mirodatos, C. Chem. Eng. J. 2009, 155, 553.

(7) Cavenati, S.; Grande, C. A.; Rodrigues, A. E. J. Chem. Eng. Data 2004, 49, 1095.

(8) Hedin, N.; Chen, L.; Laaksonen, A. Nanoscale 2010, 2, 1819.

(9) Belmabkhout, Y.; Sayari, A. Chem. Eng. Sci. 2009, 64, 3729.

(10) Ferey, G.; Serre, C.; Devic, T.; Maurin, G.; Jobic, H.; Llewellyn, P. L.; De Weireld, G.; Vimont, A.; Daturi, M.; Chang, J.-S. Chem. Soc. Rev. 2011, 40, 550.

(11) Sumida, K.; Horike, S.; Kaye, S. S.; Herm, Z. R.; Queen, W. L.; Brown, C. M.; Grandjean, F.; Long, G. J.; Dailly, A.; Long, J. R. Chem. Sci. 2010, 1, 184.

(12) Zhang, Z. J.; Li, Z., Li, J., Langmuir 2012, 28, 12122.

(13) Poloni, R.; Smit, B.; Neaton, J. B. J. Am. Chem. Soc. 2012, 134, 6714.

(14) Haldoupis, E.; Nair, S.; Sholl, D. S. J. Am. Chem. Soc. 2012, 134, 4313.

(15) Choi, H.; Park, Y. C.; Kim, Y.-H.; Lee, Y. S. J. Am. Chem. Soc. 2011, 133, 2084.

(16) Tanaka, H.; Kawamata, Y.; Simizu, H.; Fujita, T.; Yanagisawa, H.; Otani, S.; Oshima, C. Solid State Commun. 2005, 136, 22.

(17) Wu, X.; Pei, Y.; Zeng, X. C. Nano Lett. 2009, 9, 1577.

(18) An, H.; Liu, C.-s.; Zeng, Z.; Fan, C.; Ju, X. Appl. Phys. Lett. 2011, 98.

(19) Li, X.; Xu, Y.; Dong, J. Phys. Rev. A 2011, 375, 2733.

(20) Dai, J.; Li, Z.; Yang, J.; Hou, J. Nanoscale 2012, 4, 3032.

(21) Li, G.; Li, R. Physica B 2012, 407, 3419.

(22) Shahrokhi, M.; Naderi, S.; Fathalian, A. Solid State Commun. 2012, 152, 1012.

(23) Zhao, Y.; Truhlar, D. G. J. Chem. Theory Comput. 2007, 3, 289.

(24) Thanthiriwatte, K. S.; Hohenstein, E. G.; Burns, L. A.; Sherrill, C. D. J. Chem. Theory Comput. 2011, 7, 88.

(25) Delley, B. J. Chem. Phys. 1990, 92, 508.

(26) Delley, B. J. Chem. Phys. 2000, 113, 7756.

(27) Perdew, J. P.; Burke, K.; Ernzerhof, M. Phys. Rev. Lett. 1996, 77, 3865.

(28) Grimme, S. J. Comput. Chem. 2006, 27, 1787.

(29) Pulay, P. J. Comput. Chem. 1982, 3, 556. 
(30) Sun, Q.; Li, Z.; Searles, D. J.; Du, A. J. Fuel 2013, http://dx.doi.org/10.1016/j.fuel.2013.03.032.

(31) Perdew, J. P.; Wang, Y. Phys. Rev. B 1992, 45, 13244.

(32) Sun, Q.; Li, Z.; Wang, M.; Du, A.; Smith, S. C. Chem. Phys. Lett. 2012, 550, 41.

(33) Sun, Q.; Altarawneh, M. N.; Dlugogorski, B. Z.; Kennedy, E. M.; Mackie, J. C. Environ. Sci. Technol. 2007, 41, 5708.

(34) Sun, Q.; Bu, Y. X.; Qin, M. J. Phys. Chem. A 2003, 107, 1584.

(35) Sun, Q.; Li, Z.; Du, A.; Chen, J.; Zhu, Z.; Smith, S. C. Fuel 2012, 96, 291.

(36) Sun, Q.; Li, Z.; Lan, Z.; Pfisterer, C.; Doerr, M.; Fischer, S.; Smith, S. C.; Thiel, W. Phys. Chem. Chem. Phys. 2012, 14, 11413.

(37) Sun, Q.; Mackie, J. C.; Dlugogorski, B. Z.; Kennedy, E. M. Chem. Phys. Lett. 2007, 436, 68 .

(38) Li, D.; Ai, H. J. Phys. Chem. B 2009, 113, 11732.

(39) Ai, H.; Zhang, C.; Li, Y.; Zhang, L.; Li, F. J. Phys. Chem. B 2007, 111, 13786.

(40) Bader, R. F. W. Atoms in Molecules: A Quantum Theory; Oxford University Press: New York, 1990.

(41) Halgren, T. A.; Lipscomb, W. N. Chem. Phys. Lett. 1977, 49, 225.

(42) Mulliken, R. S. J. Chem. Phys. 1955, 23, 1833.

(43) Cao, F.; Ren, W.; Ji, Y.-m.; Zhao, C. Nanotechnology 2009, 20, 145703.

(44) Yang, L.; Jiang, S.; Zhao, Y.; Zhu, L.; Chen, S.; Wang, X.; Wu, Q.; Ma, J.; Ma, Y.; Hu, Z. Angew. Chem. Int. Ed. 2011, 50, 7132.

(45) Chu, S.; Majumdar, A. Nature 2012, 488, 294.

(46) Novoselov, K. S.; Geim, A. K.; Morozov, S. V.; Jiang, D.; Katsnelson, M. I.; Grigorieva, I. V.; Dubonos, S. V.; Firsov, A. A. Nature 2005, 438, 197.

(47) Ramesh, P.; Itkis, M. E.; Bekyarova, E.; Wang, F.; Niyogi, S.; Chi, X.; Berger, C.; de Heer, W.; Haddon, R. C. J. Am. Chem. Soc. 2010, 132, 14429.

(48) Zinin, P. V.; Liu, X. R.; Ming, L. C.; Sharma, S. K.; Liu, Y.; Hong, S. M. Diam. Relat. Mater. 2009, 18, 1123.

(49) Monteiro, F. H.; Larrude, D. G.; Maia da Costa, M. E. H.; Terrazos, L. A.; Capaz, R. B.; Freire, F. L., Jr. J. Phys. Chem. C 2012, 116, 3281.

(50) Lyu, S. C.; Han, J. H.; Shin, K. W.; Sok, J. H. Carbon 2011, 49, 1532. 


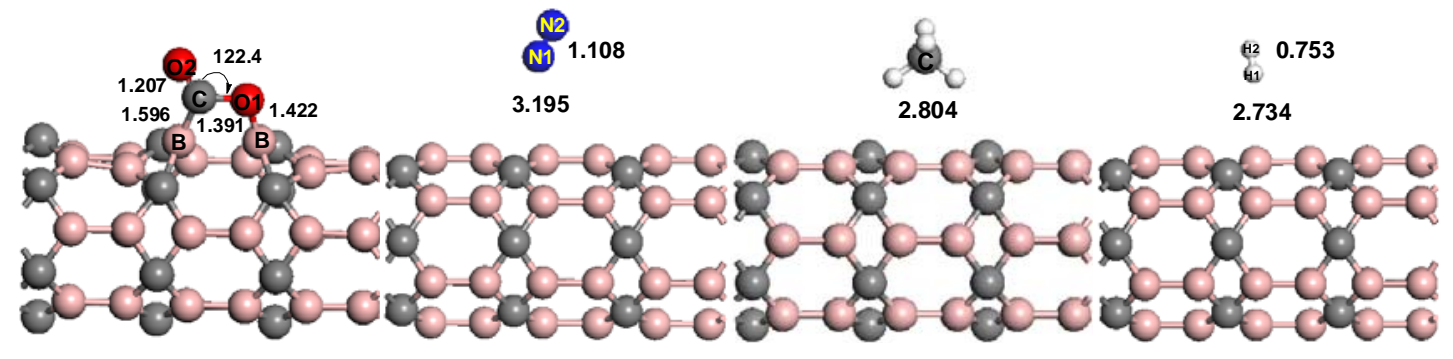
(a) $\mathrm{CO}_{2} \mathrm{~B}_{2} \mathrm{CNT}(6,0)$
(b) $\mathrm{N}_{2} \_\mathrm{B}_{2} \mathrm{CNT}(6,0)$
(c) $\mathrm{CH}_{4} \mathrm{~B}_{2} \mathrm{CNT}(6,0)$
(d) $\mathrm{H}_{2} \mathrm{~B}_{2} \mathrm{CNT}(6,0)$

Figure 1
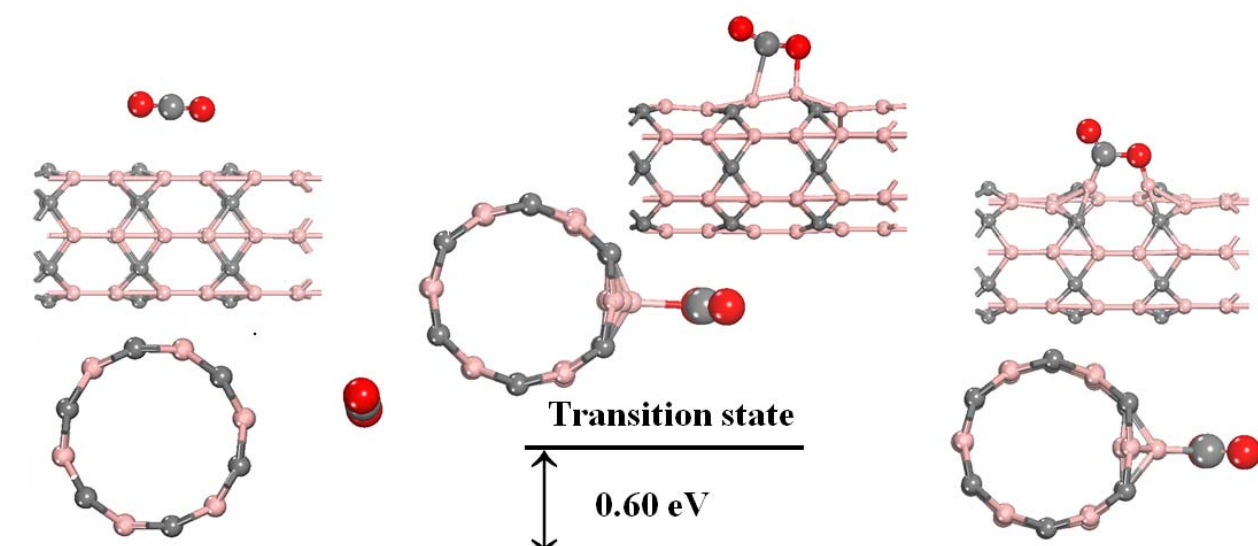

$0.15 \mathrm{eV}$

Initial state

(Physisorption)

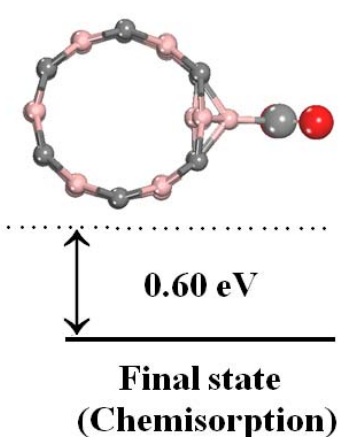

Figure 2
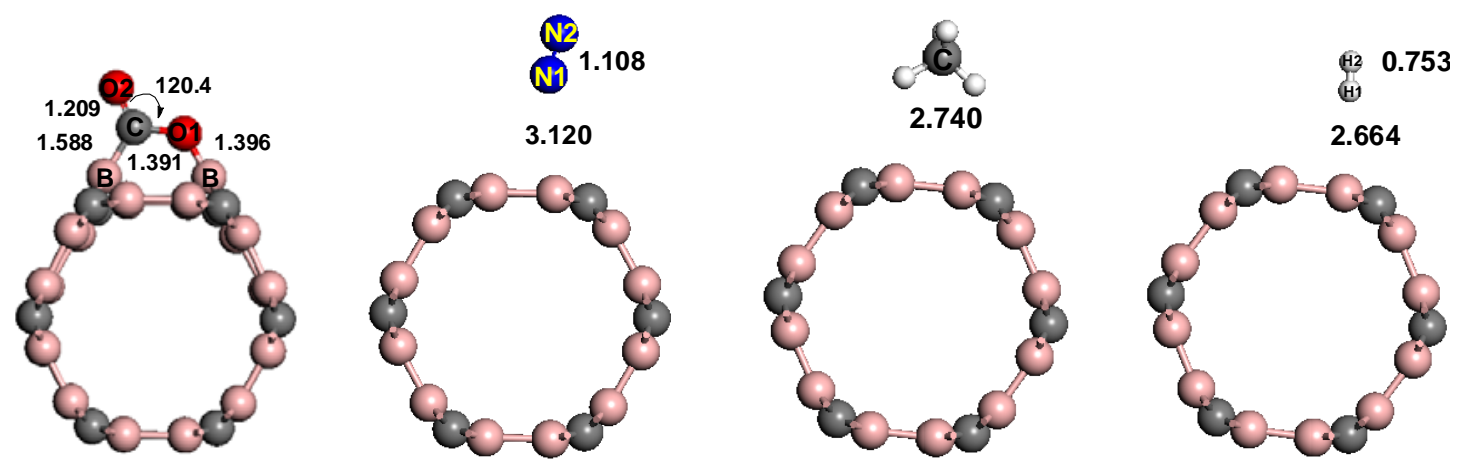
(a) $\mathrm{CO}_{2} \mathrm{~B}_{2} \mathrm{CNT}(0,6)$
(b) $\mathrm{N}_{2} \mathrm{~B}_{2} \mathrm{CNT}(0,6)$
(c) $\mathrm{CH}_{4} \_\mathrm{B}_{2} \mathrm{CNT}(0,6)$
(d) $\mathrm{H}_{2} \mathrm{~B}_{2} \mathrm{CNT}(0,6)$

Figure 3 


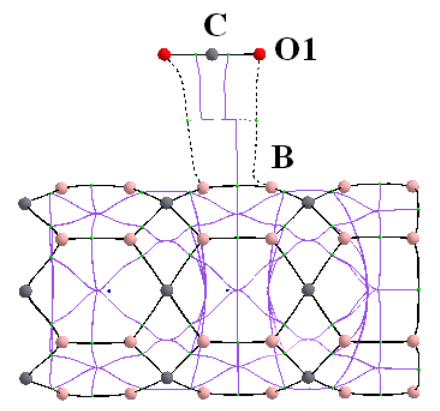

(a) $\mathrm{CO}_{2} \_\mathrm{B}_{2} \mathrm{CNT}(6,0) \_$Phy

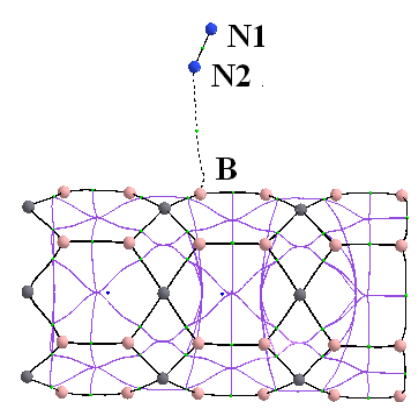

(d) $\mathrm{N}_{2} \mathrm{~B}_{2} \mathrm{CNT}(6,0)$

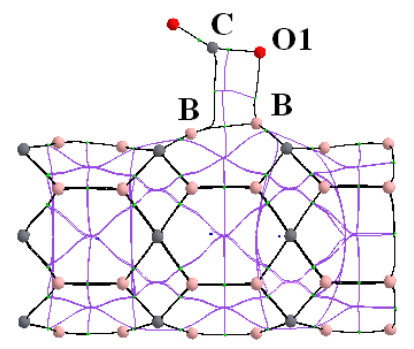

(b) $\mathrm{CO}_{2} \mathrm{~B}_{2} \mathrm{CNT}(6,0) \_\mathrm{TS}$

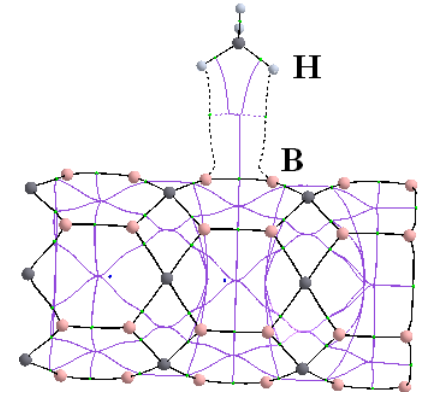

(e) $\mathrm{CH}_{4} \mathrm{~B}_{2} \mathrm{CNT}(6,0)$

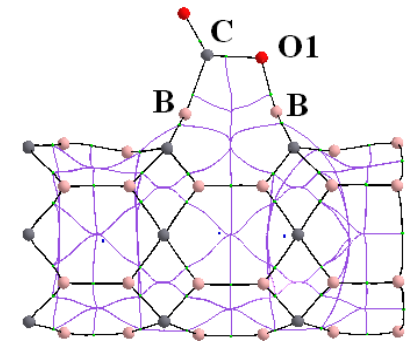

(c) $\mathrm{CO}_{2} \mathrm{~B}_{2} \mathrm{CNT}(6,0)$ _chem

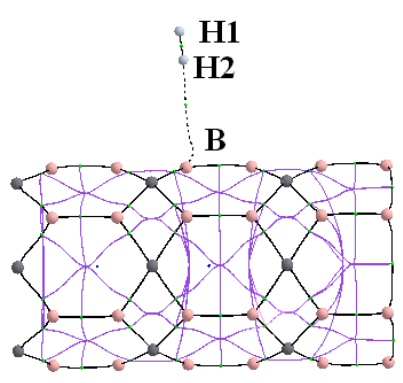

(f) $\mathrm{H}_{2} \mathrm{~B}_{2} \mathrm{CNT}(6,0)$

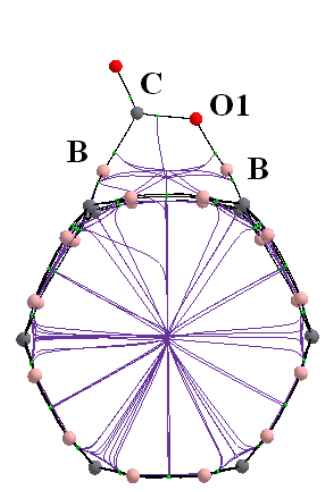

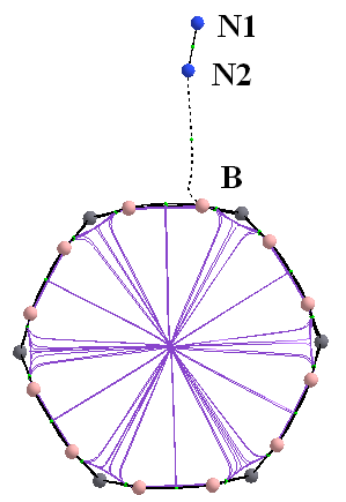

(h) $\mathrm{N}_{2} \mathrm{~B}_{2} \mathrm{CNT}(0,6)$

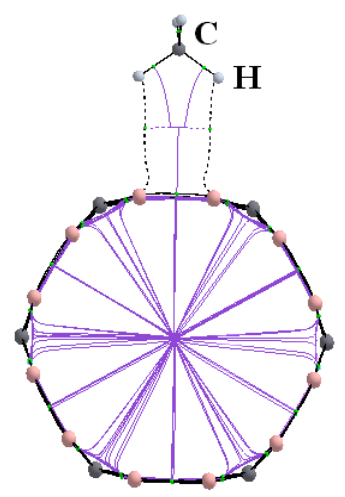

(i) $\mathrm{CH}_{4}{ }_{-} \mathrm{B}_{2} \mathrm{CNT}(0,6)$

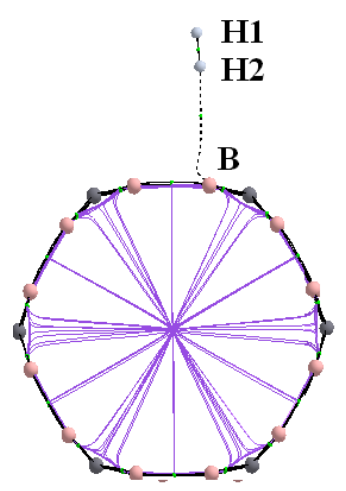

(j) $\mathrm{H}_{2} \_\mathrm{B}_{2} \mathrm{CNT}(0,6)$

(g) $\mathrm{CO}_{2} \_\mathrm{B}_{2} \mathrm{CNT}(0,6)$

Figure 4 


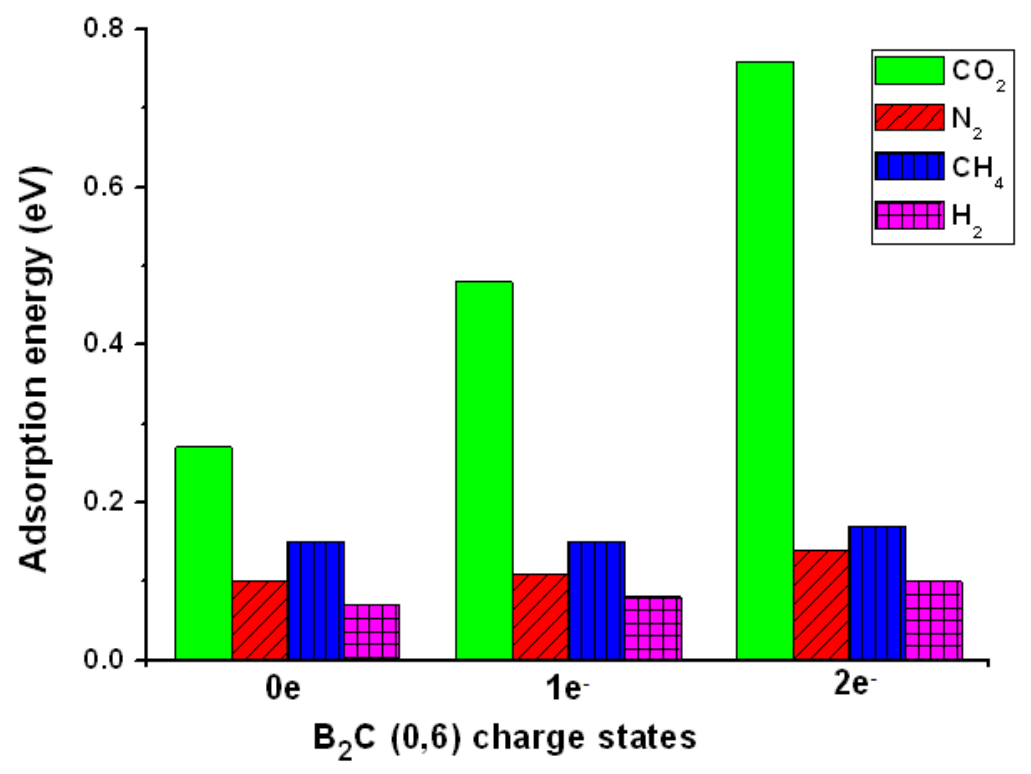

Figure 5 
Table 1. Adsorption energy in $\mathrm{eV}$, bond distance (r) in $\AA$ and bond angle $(\alpha)$ in deg of $\mathrm{CO}_{2}, \mathrm{CH}_{4}, \mathrm{~N}_{2}$ and $\mathrm{H}_{2}$ adsorption on $\mathrm{B}_{2} \mathrm{CNT}(6,0)$.

\begin{tabular}{llccc}
\hline Models & & Physisorption & Transition state & Chemisorption \\
\hline $\mathrm{CO}_{2}$ & Adsorption energy & 0.15 & -0.60 & 0.60 \\
& $\mathrm{r}(\mathrm{B}-\mathrm{O} 1)$ & 3.291 & 1.828 & 1.422 \\
& $\mathrm{r}(\mathrm{B}-\mathrm{C})$ & 3.259 & 2.281 & 1.596 \\
& $\mathrm{r}(\mathrm{C}-\mathrm{O} 1)$ & 1.176 & 1.179 & 1.207 \\
& $\mathrm{r}(\mathrm{C}-\mathrm{O} 2)$ & 1.176 & 1.230 & 1.391 \\
& $\mathrm{r}(\mathrm{B}-\mathrm{B})$ & 1.668 & 1.719 & 2.327 \\
& $\alpha(\mathrm{O}-\mathrm{C}-\mathrm{O})$ & 179.8 & 155.0 & 122.4 \\
$\mathrm{~N}_{2}$ & Adsorption energy & 0.09 & & \\
& $\mathrm{r}(\mathrm{B} \ldots \mathrm{N} 1)$ & 3.195 & & \\
& $\mathrm{r}(\mathrm{N} 1-\mathrm{N} 2)$ & 1.108 & & \\
$\mathrm{CH}_{4}$ & $\alpha(\mathrm{N} 2-\mathrm{N} 1-\mathrm{B})$ & 148.3 & & \\
& Adsorption energy & 0.13 & & \\
& $\mathrm{r}(\mathrm{B} \ldots \mathrm{C})$ & 3.524 & & \\
$\mathrm{H}_{2}$ & $\mathrm{r}(\mathrm{B} \ldots \mathrm{H})$ & 2.804 & & \\
& Adsorption energy & 0.06 & & \\
& $\mathrm{r}(\mathrm{B} \ldots \mathrm{H} 1)$ & 2.734 & & \\
& $\mathrm{r}(\mathrm{H} 1-\mathrm{H} 2)$ & 0.753 & & \\
& $\alpha(\mathrm{H} 2-\mathrm{H} 1-\mathrm{B})$ & 167.5 & & \\
\hline
\end{tabular}


Table 2. Adsorption energy in $\mathrm{eV}$, bond distance (r) in $\AA$ and bond angle $(\alpha)$ in deg of $\mathrm{CO}_{2}, \mathrm{CH}_{4}, \mathrm{~N}_{2}$ and $\mathrm{H}_{2}$ adsorption on $\mathrm{B}_{2} \mathrm{CNT}(0,6)$ with different charge states.

\begin{tabular}{|c|c|c|c|c|c|}
\hline Gases & & & $0 \mathrm{e}$ & $1 \mathrm{e}^{-}$ & $2 e^{-}$ \\
\hline \multirow[t]{7}{*}{$\mathrm{CO}_{2}$} & physisorption & Adsorption energy & 0.14 & 0.15 & 0.19 \\
\hline & & $\mathrm{r}(\mathrm{B}-\mathrm{O} 1)$ & 3.187 & 3.177 & 3.154 \\
\hline & & $\mathrm{r}(\mathrm{B}-\mathrm{C})$ & 3.238 & 3.259 & 3.259 \\
\hline & & $\mathrm{r}(\mathrm{C}-\mathrm{O} 2)$ & 1.176 & 1.176 & 1.176 \\
\hline & & $\mathrm{r}(\mathrm{C}-\mathrm{O} 1)$ & 1.177 & 1.176 & 1.177 \\
\hline & & $\mathrm{r}(\mathrm{B}-\mathrm{B})$ & 1.677 & 1.676 & 1.677 \\
\hline & & $\alpha(\mathrm{O}-\mathrm{C}-\mathrm{O})$ & 177.2 & 178.7 & 179.9 \\
\hline \multirow[t]{7}{*}{$\mathrm{CO}_{2}$} & chemisorption & Adsorption energy & 0.27 & 0.48 & 0.76 \\
\hline & & $\mathrm{r}(\mathrm{B}-\mathrm{O} 1)$ & 1.396 & 1.411 & 1.427 \\
\hline & & $\mathrm{r}(\mathrm{B}-\mathrm{C})$ & 1.588 & 1.590 & 1.594 \\
\hline & & $\mathrm{r}(\mathrm{C}-\mathrm{O} 2)$ & 1.209 & 1.217 & 1.226 \\
\hline & & $\mathrm{r}(\mathrm{C}-\mathrm{O} 1)$ & 1.391 & 1.380 & 1.371 \\
\hline & & $\mathrm{r}(\mathrm{B}-\mathrm{B})$ & 2.899 & 2.904 & 2.917 \\
\hline & & $\alpha(\mathrm{O}-\mathrm{C}-\mathrm{O})$ & 120.4 & 119.8 & 119.2 \\
\hline \multirow[t]{4}{*}{$\mathrm{N}_{2}$} & physisorption & Adsorption energy & 0.10 & 0.11 & 0.14 \\
\hline & & $\mathrm{r}(\mathrm{B} \ldots \mathrm{N} 1)$ & 3.120 & 3.096 & 3.159 \\
\hline & & $\mathrm{r}(\mathrm{N} 1-\mathrm{N} 2)$ & 1.108 & 1.109 & 1.110 \\
\hline & & $\alpha(\mathrm{N} 2-\mathrm{N} 1-\mathrm{B})$ & 163.0 & 104.7 & 98.6 \\
\hline \multirow[t]{3}{*}{$\mathrm{CH}_{4}$} & physisorption & Adsorption energy & 0.15 & 0.15 & 0.17 \\
\hline & & $\mathrm{r}(\mathrm{B} \ldots \mathrm{C})$ & 3.474 & 2.495 & 3.510 \\
\hline & & $\mathrm{r}(\mathrm{B} \ldots \mathrm{H})$ & 2.740 & 2.717 & 2.718 \\
\hline \multirow[t]{4}{*}{$\mathrm{H}_{2}$} & physisorption & Adsorption energy & 0.07 & 0.08 & 0.10 \\
\hline & & $\mathrm{r}(\mathrm{B} \ldots \mathrm{H} 1)$ & 2.664 & 2.681 & 2.675 \\
\hline & & $\mathrm{r}(\mathrm{H} 1-\mathrm{H} 2)$ & 0.753 & 0.754 & 0.755 \\
\hline & & $\alpha(\mathrm{H} 2-\mathrm{H} 1-\mathrm{B})$ & 178.7 & 174.7 & 171.5 \\
\hline
\end{tabular}


Table 3. Mulliken change distribution of configurations of $\mathrm{CO}_{2}, \mathrm{~N}_{2}, \mathrm{CH}_{4}$ and $\mathrm{H}_{2}$ adsorption on $\mathrm{B}_{2} \mathrm{CNT}$ s and charge transfer $(\mathrm{CT})$ from $\mathrm{B}_{2} \mathrm{CNT}$ s to gases of the configurations.

\begin{tabular}{lllcccc}
\hline & & & $\mathrm{B}_{2} \mathrm{CNT}(6,0)$ & & $\mathrm{B}_{2} \mathrm{CNT}(0,6)$ \\
\hline Gases & & atoms & $0 \mathrm{e}$ & $0 \mathrm{e}$ & $1 \mathrm{e}^{-}$ & $2 \mathrm{e}^{-}$ \\
\hline $\mathrm{CO}_{2}$ & physisorption & $\mathrm{O} 1$ & -0.287 & -0.281 & -0.288 & -0.292 \\
& & $\mathrm{C}$ & 0.579 & 0.572 & 0.569 & 0.567 \\
& & $\mathrm{O} 2$ & -0.290 & -0.288 & -0.290 & -0.295 \\
& chemisorption & $\mathrm{CT}$ & 0.002 & 0.003 & -0.009 & -0.02 \\
& & $\mathrm{O} 1$ & -0.346 & -0.342 & -0.394 & -0.424 \\
& & $\mathrm{C}$ & 0.360 & 0.355 & 0.356 & 0.357 \\
& & $\mathrm{O} 2$ & -0.384 & -0.396 & -0.410 & -0.445 \\
$\mathrm{~N}_{2}$ & physisorption & $\mathrm{CT}$ & -0.370 & -0.383 & -0.448 & -0.512 \\
& & $\mathrm{~N} 1$ & 0.030 & 0.030 & 0.005 & 0.028 \\
& & $\mathrm{~N} 2$ & -0.022 & -0.022 & -0.012 & -0.064 \\
$\mathrm{CH}_{4}$ & physisorption & $\mathrm{CT}$ & 0.008 & 0.008 & -0.007 & -0.036 \\
& & $\mathrm{C} 1$ & -0.370 & -0.383 & -0.379 & -0.375 \\
& & 0.093 & 0.105 & 0.113 & 0.121 \\
& & $\mathrm{H} 2$ & 0.090 & 0.091 & 0.074 & 0.056 \\
& & $\mathrm{H} 3$ & 0.091 & 0.092 & 0.072 & 0.053 \\
& & $\mathrm{H} 4$ & 0.094 & 0.104 & 0.115 & 0.126 \\
$\mathrm{H}_{2}$ & physisorption & $\mathrm{CT}$ & -0.002 & 0.009 & -0.005 & -0.019 \\
& & $\mathrm{H} 1$ & 0.003 & 0.003 & 0.039 & 0.077 \\
& & $\mathrm{H} 2$ & -0.004 & -0.004 & -0.047 & -0.092 \\
& & $\mathrm{CT}$ & -0.001 & -0.001 & -0.008 & -0.015 \\
\hline
\end{tabular}

